Division of Infectious Disease, Key Laboratory of Surveillance and Early Warning on Infectious Disease, Chinese Centre for Disease Control and Prevention, Beijing, China

2 Chinese Centre for Disease Control and Prevention, Beijing, China

3 WorldPop, School of Geography and Environmental Science, University of Southampton, Southampton, UK

4 CAS Key Laboratory of Pathogenic Microbiology and Immunology, Institute of Microbiology, Chinese Academy of Sciences, Beijing, China

Correspondence to: G F Gao gaofu@chinacdc.cn

Cite this as: BMJ 2021;375:e066169 http://dx.doi.org/10.1136/BMI-2021-066169

Published: 02 December 2021

CHINA'S RESPONSE TO COVID-19

\title{
Rapid and sustained containment of covid-19 is achievable and worthwhile: implications for pandemic response
}

Qiulan Chen and colleagues argue that innovative technological and organisational approaches can overcome important challenges to containment measures early in a pandemic

Qiulan Chen, ${ }^{1}$ Lance Rodewald, ${ }^{2}$ Shengjie Lai, ${ }^{3}$ George F Gao 2,4

In the 20 months since the World Health Organization declared covid-19 to be a pandemic, more than 250 million cases have been confirmed. More than 5 million deathshave occurred disproportionately by country, with $10 \%$ of countries reporting $80 \%$ of cases. ${ }^{1}$ In a new pandemic, with no vaccines prepared, non-pharmaceutical interventions are the only response. In the first year of the covid-19 pandemic, several countries that aimed to completely interrupt community transmission-China, Singapore, Australia, and New Zealand-achieved and maintained containment. ${ }^{23}$ Here, we analyse China's containment strategy before vaccine roll-out and describe measures for initial and sustained containment and benefits for the country.

Containment of covid-19 means stopping transmission of SARS-CoV-2. ${ }^{4}$ Core measures of containment include actively finding infected people and treatment in isolation, close contact tracing and quarantine, and restrictions of travel from areas with community transmission. Additional measures that reduce transmission include stay at home orders, cancellation of mass gatherings, closing schools, and use of personal protection measures, such as hand hygiene, respiratory etiquette, keeping at least $1 \mathrm{~m}$ distance, and mask wearing. ${ }^{5}$

Sustained containment is maintaining elimination of SARS-CoV-2 by completely stopping all externally introduced outbreaks-a policy of "zero tolerance for local transmission (zero covid).” Responses to an outbreak are based on an assessment of the epidemic risk and use the same measures as those used for the initial containment. These measures are augmented by strict border protection to minimise the number of imported outbreaks and by surveillance for infection using highly sensitive, routine polymerase chain reaction (PCR). Table 1 shows the initial and sustained containment measures based on assessment of the risk of epidemic. 
Table 1 | Selected containment measures against covid-19 in epidemic phases and areas, based on risk assessment.

\begin{tabular}{|c|c|c|c|c|c|}
\hline \multirow{2}{*}{ Measure } & \multirow{2}{*}{ Measure component } & \multirow{2}{*}{ For initial containment* } & \multicolumn{3}{|c|}{ For sustained containment* } \\
\hline & & & Low risk areast & Medium risk areas & High risk areas \\
\hline \multirow{6}{*}{ Active case finding } & PCR screening in fever clinics & + & + & + & + \\
\hline & $\begin{array}{l}\text { PCR screening at hospital } \\
\text { admission }\end{array}$ & + & + & + & + \\
\hline & $\begin{array}{l}\text { PCR screening of international } \\
\text { travellers }\end{array}$ & + & + & + & + \\
\hline & $\begin{array}{l}\text { Routine PCR screening of key } \\
\text { populations at high risk } \neq\end{array}$ & - & + & + & + \\
\hline & $\begin{array}{l}\text { Screening travellers from high } \\
\text { risk areas }\end{array}$ & + & + & + & + \\
\hline & City-wide mass PCR screening & + & - & - & + \\
\hline \multirow{2}{*}{ Case management } & $\begin{array}{l}\text { Isolated treatment in } \\
\text { designated hospitals }\end{array}$ & + & + & + & + \\
\hline & $\begin{array}{l}\text { Fangcang shelter hospitals for } \\
\text { patients with mild illness }\end{array}$ & + & - & - & - \\
\hline \multirow{2}{*}{$\begin{array}{l}\text { Contact tracing and } \\
\text { management }\end{array}$} & Contact tracing & + & + & + & + \\
\hline & $\begin{array}{l}\text { Centralised individual } \\
\text { quarantine with PCR testing§ }\end{array}$ & + & + & + & + \\
\hline \multirow{4}{*}{ Border control } & Visa restrictions & + & + & + & + \\
\hline & $\begin{array}{l}\text { Reduced international airline } \\
\text { flights and port closures }\end{array}$ & + & + & + & + \\
\hline & $\begin{array}{l}\text { Suspension of international } \\
\text { travel over land and water }\end{array}$ & + & + & + & + \\
\hline & $\begin{array}{l}14 \text { day quarantine and PCR } \\
\text { testing for every person } \\
\text { entering from abroad§ }\end{array}$ & + & + & + & + \\
\hline Routine control & $\begin{array}{l}\text { Individual risk screening in key } \\
\text { institutions and public places }\end{array}$ & + & + & + & + \\
\hline Mask wearing & $\begin{array}{l}\text { Required in indoor public } \\
\text { areas, hospitals, and public } \\
\text { transportation }\end{array}$ & + & + & + & + \\
\hline \multirow{4}{*}{ Domestic travel restrictions } & $\begin{array}{l}\text { Lockdown of communities } \\
\text { with cases }\end{array}$ & + & - & + & + \\
\hline & Lockdown of high risk areas & + & - & + & + \\
\hline & Lockdown of an entire city $^{\star *}$ & + & - & - & When necessary \\
\hline & $\begin{array}{l}\text { Travel restrictions of high risk } \\
\text { population based on health } \\
\text { code smartphone appst† }\end{array}$ & + & + & + & + \\
\hline \multirow{4}{*}{ Social distancing } & Cancel mass gatherings & + & - & + & + \\
\hline & Close entertainment places & + & - & + & + \\
\hline & 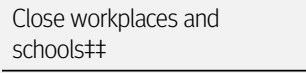 & + & - & - & When necessary \\
\hline & Stay at home orders & + & - & - & When necessary \\
\hline Social mobilisation & $\begin{array}{l}\text { Health education and risk } \\
\text { communication press releases } \\
\text { and media briefings }\end{array}$ & + & - & + & + \\
\hline
\end{tabular}


Table 1 | Selected containment measures against covid-19 in epidemic phases and areas, based on risk assessment. (Continued)

\begin{tabular}{|c|c|c|c|}
\hline \multirow{2}{*}{ Measure } & \multirow{2}{*}{ Measure component } & \multicolumn{2}{|c|}{ For sustained containment* } \\
\hline & & Medium risk areas & High risk areas \\
\hline \multicolumn{4}{|c|}{$P C R=$ polymerase chain reaction. } \\
\hline \multicolumn{4}{|c|}{ * The initial containment phase refers to Wuhan lockdown from 23 January to 7 April 72020 ; the sustained containment phase refers to 8 April 2020 and after. } \\
\hline \multicolumn{4}{|c|}{$\begin{array}{l}\text { † Low risk area: any county/district that has reported no covid-19 cases (China has more than } 2800 \text { counties and districts); medium risk area: any county/district that has one case of covid-19 but no sign of commun } \\
\text { transmission; high risk area: any county/district that has community transmission. }\end{array}$} \\
\hline \multicolumn{4}{|c|}{$\begin{array}{l}\text { ‡ Key populations are those with frequent contact with entry staff and imported goods workers (staff working at ports, quarantine locations, international road freight drivers, and port handlers); healthcare workers; staff } \\
\text { working in closed places, such as institutions providing long term care and prisons; staff providing public services (public transportation staff and staff in airports, museum, and libraries); and workers in businesses and wet } \\
\text { markets. Key venues included hospitals, the above mentioned venues, and also quarantine hotels and designated hospitals for treatment of patients with covid-19. }\end{array}$} \\
\hline \multicolumn{4}{|c|}{ १ Fangcang shelter hospitals were used only in Wuhan. } \\
\hline \multicolumn{4}{|c|}{$\begin{array}{l}\S \text { According to the } 8 \text { th national protocol, issued in May 2021, during quarantine, international travellers and close contacts are required to take PCR testing on days } 1,4,7 \text {, and } 14 \text {; after release from quarantine, to stay a } \\
\text { home for seven days of health monitoring, with PCR testing on days } 2 \text { and } 7 \text {. }\end{array}$} \\
\hline \multicolumn{4}{|c|}{${ }^{\star \star}$ City lockdowns were of short duration outside Wuhan. } \\
\hline \multicolumn{4}{|c|}{$\begin{array}{l}\text { †+ Health code: an electronic pass system, implemented in } 5 \mathrm{G} \text { networks through smartphone apps, which has access to centralised data for recent travel to epidemic areas, vaccination status, and PCR test results; healt } \\
\text { codes score individual risk status with colour codes; free movement is allowed with green codes (no recent travel to an outbreak area). }\end{array}$} \\
\hline
\end{tabular}

\section{Benefits of rapid and sustained containment}

Rapid containment avoids most deaths and hastens socioeconomic recovery and return to normal societal functioning. During the containment process in mainland China between January and March 2020, the total mortality rate in areas outside Hubei province was close to the 2015-19 rate (675 per 100 ooo during containment versus 715 historically), with considerably lower death rates from pneumonia, chronic respiratory diseases, and traffic accidents. ${ }^{6}$ Sustained containment prevented a destructive second wave, with only three covid-19 related deaths among 15500 cases (case-fatality ratio $<0.05 \%$ ) from April 2020 through March 2021 in mainland China. ${ }^{7}$ Seasonally adjusted growth in gross domestic product, which was negative during containment in the first quarter of 2020, became positive after containment, attaining a $6.5 \%$ growth rate within the year; domestic air travel returned to normal within 6 months of containment (fig 1). Surveys of citizens of 19 large countries with major covid-19 epidemics, to assess their perception of the responses of their governments to the pandemic, showed that the responses of China and South Korea were rated highest. ${ }^{8}$ 


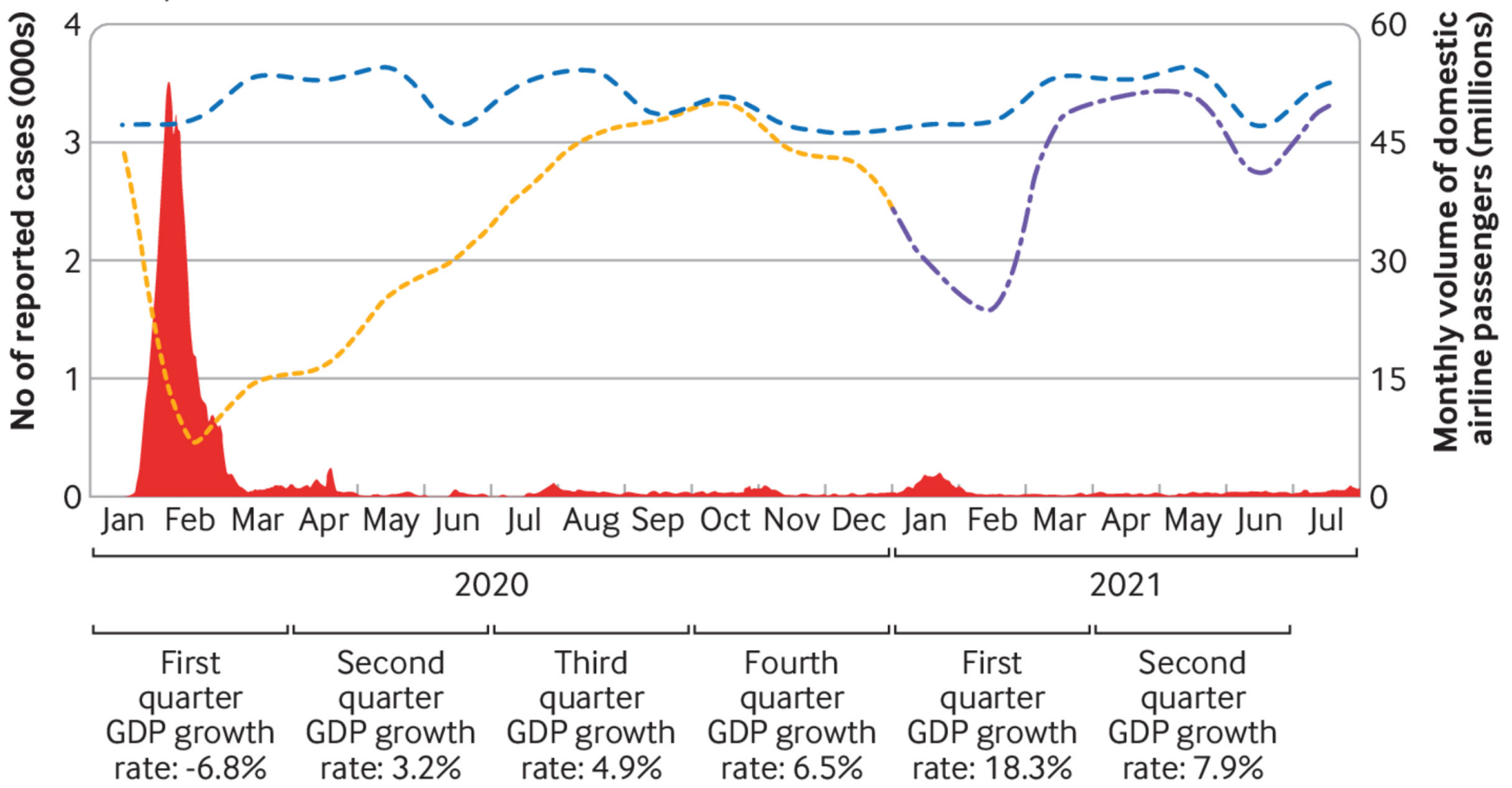

Fig 1 | Domestic flights and seasonal gross domestic product (GDP) in different covid-19 epidemic situations. The blue dashed line indicates the level of domestic flights that would have been expected based on the 2019 volume of domestic airline passengers

\section{How was containment achieved and sustained in China?}

Containment was the outcome of a response by the whole of government and all the people to covid-19. ${ }^{8}$ SARS-CoV-2 emerged without warning and was found to be responsible for a cluster of cases of pneumonia of unknown cause in Wuhan. Within two weeks of recognition of the cluster, the virus was isolated, identified, and sequenced, and its sequence was shared globally, enabling development of PCR diagnostics and gene based vaccines. Once the epidemic potential of the virus was realised, the government of China invoked an emergency response system that had been developed in the wake of SARS for a wide variety of emergencies. The government declared the virus, now called covid-19, to be a level 2 infectious disease to be managed with a level 1 response-similar to the management of poliomyelitis. ${ }^{910}$

China's State Council established a national, multisectoral, joint prevention and control mechanism and required all levels of government to establish corresponding prevention and control headquarters, with the head of local government as director, and heads of ports, health, transportation, public security, and information departments as members. Every school, work unit, and community established a working group against covid-19. Management was based on a grid: communities were subdivided with buildings as subunits and their managers responsible for ensuring strict fulfilment of control measures. Community volunteers helped with control activities, such as measurement of temperature on entry, health education, health monitoring of people returning from high risk areas, providing services to people under lockdown, and ensuring high compliance with prevention and control measures. Strict organisational management, social cohesiveness, and the altruistic values of citizens were the "magic weapons" used to combat covid-19 during this phase.

\section{Actively finding patients and their management}

Actively finding patients and their management means early detection, treatment of every patient in isolation, and identifying close contacts of patients for placement in 14 days of individual, mandatory quarantine with periodic PCR testing. ${ }^{4}$ Early detection and isolation of patients was the single most effective technique for containing the virus because it interrupted transmission chains before they could lengthen. ${ }^{3}$

\section{Rapid expansion of PCR capacity}

PCR tests had to be completed within six hours for every patient suspected of having the virus-from collection of samples to reporting of results. For example, to meet this requirement, PCR capacity in Wuhan was increased from 200 tests a day before lockdown to 2000 tests a day on 28 January 2020, and then to 35 ooo tests a day by early February 2020. This increase was accomplished by adapting medical, centres of disease control, private testing companies, and mobile laboratories to focus completely on high throughput, rapid PCR testing. As a result, the median time from onset of illness to confirmation was shortened from 15 days in early January to five days in early February in Wuhan, nationwide from 12 days to three days. ${ }^{11}$

\section{Ensuring isolation and treatment}

Patients with covid-19 could be treated only in designated hospitals. Wuhan built two new hospitals and 16 shelter hospitals, and over 40000 medical staff were deployed from across China to ensure that every patient was safely treated. The crude fatality ratio 
nationwide decreased over time from $17.3 \%$ for patients with onset of symptoms from 10 January 2020 , to $0.7 \%$ for cases with onset of symptoms after 1 February 2020. ${ }^{11}$ All healthcare workers and others at occupational risk of exposure to SARS-CoV-2 were required to use personal protective equipment, similar to the highly effective Ebola virus protective equipment.

\section{Contact tracing and quarantine}

Epidemiological surveys to identify close contacts had to be completed within 24 hours. All close contacts underwent mandatory, 14 day quarantine in designated hotels. Initially, home quarantine was required, but this was found to be associated with a $19.1 \%$ secondary attack rate among household contacts. ${ }^{12}$ Centralising quarantine reduced this secondary attack rate among household contacts from $19.1 \%$ to $4.1 \%{ }^{12}$ Contact tracing was used to identify secondary cases. For example, $74 \%$ and $65 \%$ of all cases were discovered among the close contacts in Dalian (July 2020) and Guangzhou outbreaks (May 2021).

\section{Routine screening in key populations and medical institutions}

In the sustained containment phase, weekly routine PCR screening was conducted among key populations (table 1), including workers handling imported frozen food, who had been shown to be at risk of infection, ${ }^{13} 14$ and each person seeking medical attention in every fever clinic and each inpatient once admitted, including clinics located in rural areas. With this routine screening many infections were detected in patients who were asymptomatic, thus avoiding a significant amount of secondary transmission. Outbreak index cases were identified by medical institutions for example, in the XFDM Beijing outbreak and the Dalian, Shanghai Pudong Airport, Qingdao, and Manchuria outbreaks. ${ }^{15}$

\section{Mass screening when necessary}

To reopen the economy as soon as possible, city-wide universal PCR screening is conducted and has to be completed within three to five days in counties/districts with community transmission, prioritising populations at high risk. Universal screening identified a large percentage of patients-about $22 \%$ in the July 2020 Dalian outbreak and $26 \%$ in the June 2020 Beijing outbreak.

\section{Lockdown to achieve initial containment}

Lockdown of an area or a city is suspension of all public transportation within and in and out of the area or city, together with stay at home orders for residents other than essential workers. During lockdown, community workers ensured the safety of residents and supplies of necessities for living. Lockdown can prevent external transmission when an epidemic is limited to a single geographical area. The first wave of cases was concentrated in Wuhan, so Wuhan underwent lockdown for 78 days. Without the Wuhan lockdown, China would have had an estimated 67 times as many patients with covid-19 within one month. ${ }^{3}$ A serological survey after containment showed that $4.4 \%$ of Wuhan's population had been infected. Outside of Hubei, the percentage of people infected was too small to measure in a representative sample of 10000 (two infections), showing the effectiveness of the Wuhan lockdown. ${ }^{16}$

\section{Border control}

Border control prevents almost all importation of the virus. Hundreds of SARS-CoV-2 infections are being diagnosed every month among quarantined international travellers who tested negative before boarding flights to China. Each infected person might spark an outbreak if undetected and allowed into the community. Border control allowed essential international travel during containment, such as trade related to the pandemic response-namely, test kits, personal protection equipment, and medical supplies. High volume international ports like Guangzhou and Xiamen established international health centres for quarantine of people entering and leaving, providing better infection control to minimise secondary transmission risk.

\section{Precision lockdown and movement restriction}

Prevention and control protocols were adjusted according to the evidence and to deal with new challenges. Local public security, information, and health sectors shortened epidemiologic investigation timelines to manage the more transmissible delta variant. Within one hour of a positive PCR test, local public security and information sectors use mobile phone locations to provide a preliminary temporal-spatial trajectory of infected people. Within four hours, public health professionals conduct interviews to confirm activity locations and determine how to manage places and populations at high risk and find all close contacts. Local government promptly restricts movement of high risk populations based on big data and PCR testing (box 1) and closes high risk places for disinfection.

\section{Box 1: Early detection by contact tracing and mass screening} Risk stratification of case contacts

In the sustained containment phase, China defined three levels of contacts.

- Level 1: close contacts of cases from two days before case onset to case isolation. During this time, people without effective personal protection who were in close contact with the case-household members, work colleagues in confined environments like offices, and people sharing meals and going to entertainment venues-were designated as level 1 close contacts. Level 1 contacts must be identified within 24 hours and then undergo mandatory, centralised quarantine with periodic polymerase chain reaction (PCR) testing.

- Level 2: close contacts of close contacts. Level 2 contacts have PCR testing and are quarantined for 14 days, although home quarantine can be used.

- Level 3: populations at high risk. Level 3 contacts were in the same place as a case at the same time or shortly thereafter. Level 3 contacts have PCR testing, are responsible for reporting their health status, and are recommended to limit out of home activities until the epidemic risk assessment is changed.

\section{Big data contact tracing}

China's nearly ubiquitous use of GPS enabled smartphones with app based payment capability partially solves the problem of memory gaps during contact tracing. Temporal-spatial trajectories of smartphones can be determined with varying degrees of accuracy by GPS, IP address, and sensor data from users' devices, combined with knowledge about wi-fi access points, cell towers, and Bluetooth enabled devices. An internet based mobile facility helped to identify close contacts using these trajectories during containment and in response to the outbreak. The approach required legal authorisation that came from the public health emergency declaration; data access is highly restricted to ensure protection of privacy and guarantee information security. Publicising precise locations of outbreaks with identified tracking information has been found to encourage self-monitoring and self-reporting of close contacts who might not otherwise have known they were a contact. Mass screening

Rapid point-of-care antigen testing is not used for mass screening in China owing to its low sensitivity and low positive predictive value in China, where the prevalence is low. Rapid PCR testing agents that require only 30 minutes to produce results are used instead.

A 10:1 or 5:1 pooled sample approach is used to expand the PCR capacity and increase cost effectiveness. Mobile, inflatable biosafety laboratories with modular air dome structures can be set up in one day. Use of several such inflatable laboratories helped to stop the Dalian, Qingdao, and Shijiazhuang outbreaks. 


\section{Evaluating screening effectiveness}

Using the XFDM Beijing outbreak as an example, among the 368 cases identified in this outbreak ${ }^{13}$ were

- 169 (5.1\%) cases identified from 3311 employees working at XFDM

- 103 (0.02\%) cases from the 550000 visitors to XFDM between May 30 and June 12

- 96 (0.00096\%) cases from the 10 million Beijing residents screened

Of the 368 cases, smartphone GPS methods identified 103 (28.0\%), and mass screening identified 96 (26.1\%). Given the speed of an epidemic and the large population of the area, the big data method has significant advantages over traditional contact tracing. Mass screening is critically important for rapid detection of cases and for reopening areas that have had an outbreak under the "zero covid" policy. Big data have proved useful for finding contacts in a timely manner in outbreaks caused by the more transmissible delta variant.

At any one time, almost all areas in China are low risk, therefore allowing unrestricted movement. Communities with even one case, however, are locked down until 14 days after the last case is identified. The county/district is upgraded to medium risk once it has reported any case, and residents in medium risk areas are required to avoid unnecessary travel, or, if travel is necessary, provide a PCR report within 48 hours. For community transmission, county/districts will be upgraded to high risk, and the area will be locked down, banning external travel. Box 2 describes containment of the Shijiazhuang outbreak.

Box 2: Example of the response to a covid-19 outbreak in China: the Shijiazhuang outbreak.

On 2 January 2021, Shijiazhuang City reported and promptly isolated one person with covid-19. On 3 and 4 January, 17 and 11 cases, respectively, were reported, with most located in $X$ village of $Z$ town in Gaocheng district. Time between onset and confirmation of the first cases was too long to allow identification of the source of infection, indicating community transmission. The outbreak last until 1 February and affected 869 people, with one death in Shijiazhuang City (fig 2). A total of 334 local teams and seven national/provincial teams were deployed for epidemiological investigation, and more than 20000 laboratory staff were employed for mass PCR screening.

Timeline

- On 5 January, X village was upgraded to high risk and locked down. On 6 January Shijiazhuang banned mass gatherings, stopped in-person education, and required all residents other than essential workers to stay at home. The first round of whole city polymerase chain reaction (PCR) screening was conducted from 6 to 9 January, and detected 354 cases, with most located in three villages in Z town, Gaocheng district

- On 12 January, Shijiazhuang city was locked down. The 5437 residents of the three villages at the epicentre were centrally quarantined; ultimately, 27104 people (including close contacts) were quarantined in 434 designated hotels with 27831 rooms

- From 12 to 14 January, a second round of whole city PCR screening was conducted that identified 247 cases, with 217 (88\%) located in Gaocheng district

- A third round of whole-city mass screening was conducted from 20 to 22 January, which identified only 30 cases, all in the quarantined group, suggesting that the epidemic was being controlled

- On 22 January, Shijiazhuang adjusted risk levels. Strict containment measures continued in areas of medium and high risk, with mass screening once every two days, while people in areas of low risk resumed work
- On 1 February, $60 \%$ of patients were discharged, and on 6 February, all patients with severe disease had improved

- On 8 February, Gaocheng district was declared low risk, and highways were opened

- On 22 February, Shijiazhuang restarted transportation between cities and reopened entertainment venues and public places

\section{Social distancing and personal non-pharmaceutical interventions}

Entertainment venues are closed, and mass gatherings are prohibited in areas of medium and high risk. Routine non-pharmaceutical interventions measures are strictly maintained in key public venues, including contactless temperature measurement, verifying status as health code green upon entry, limiting visitors, wearing masks, social distancing, hand hygiene, and environment sanitation. Modelling shows that the effectiveness of actively finding cases and management can be strengthened and hastened by combination with other non-pharmaceutical interventions, travel restriction, and physical distancing. ${ }^{3}$ Suspending public transport within the city, closing entertainment venues, and prohibiting mass gatherings are important to reduce transmission during containment and response to the outbreak. ${ }^{17}$

\section{Improved coordination mechanisms for better preparedness and more robust response}

The national level, multisectoral, joint prevention and control mechanism issued increasingly nuanced, evidence based preparedness and response protocols that must be observed throughout mainland China. ${ }^{18-23}$ Plans for preparedness covered epidemiology and medical teams, PCR capacity, designated hospitals, use of personal protective equipment, quarantine hotels, and community support and management. Cross regional assistance is required for rapidly containing any outbreak. Every city and county was required to increase PCR capacity sufficient to conduct screening of the whole population in three to five days. Innovation is encouraged-for example, Guangzhou developed "tripartite teams," consisting of community members and health and public security staff to enhance grid based management and improve services to people during their lockdown.

\section{Implications}

Emerging pathogens with the potential for human-to-human transmission are the main concerns of global biosecurity. ${ }^{24}{ }^{25} \mathrm{~A}$ lesson learnt in the covid-19 pandemic is that a new, highly transmissible respiratory pathogen that causes severe illness can overwhelm even well resourced health systems. In our increasingly globalised world, reliance on mitigation (that is, a strategy that aims to lower the surge and delay the peak in an epidemic to reduce healthcare demand, uses the same non-pharmaceutical interventions as containment strategy, except for active detection of cases) as the initial response to a pandemic can have disastrous consequences. A second lesson is that rapid containment is possible, desirable, and appreciated by citizens. The global community should work together to gain evidence based confidence that early containment of emerging, world threatening pathogens can be the preferred first strategy-to be attempted until either successful or proved impossible. Even if a new pathogen that might lead to a pandemic proves to be uncontainable, the containment effort is still worthwhile, as it buys time for development of drugs and vaccines and optimisation of control strategies. 
GC district upgraded to high risk area

First whole city mass screening started

All citizens stay at home for 7 days

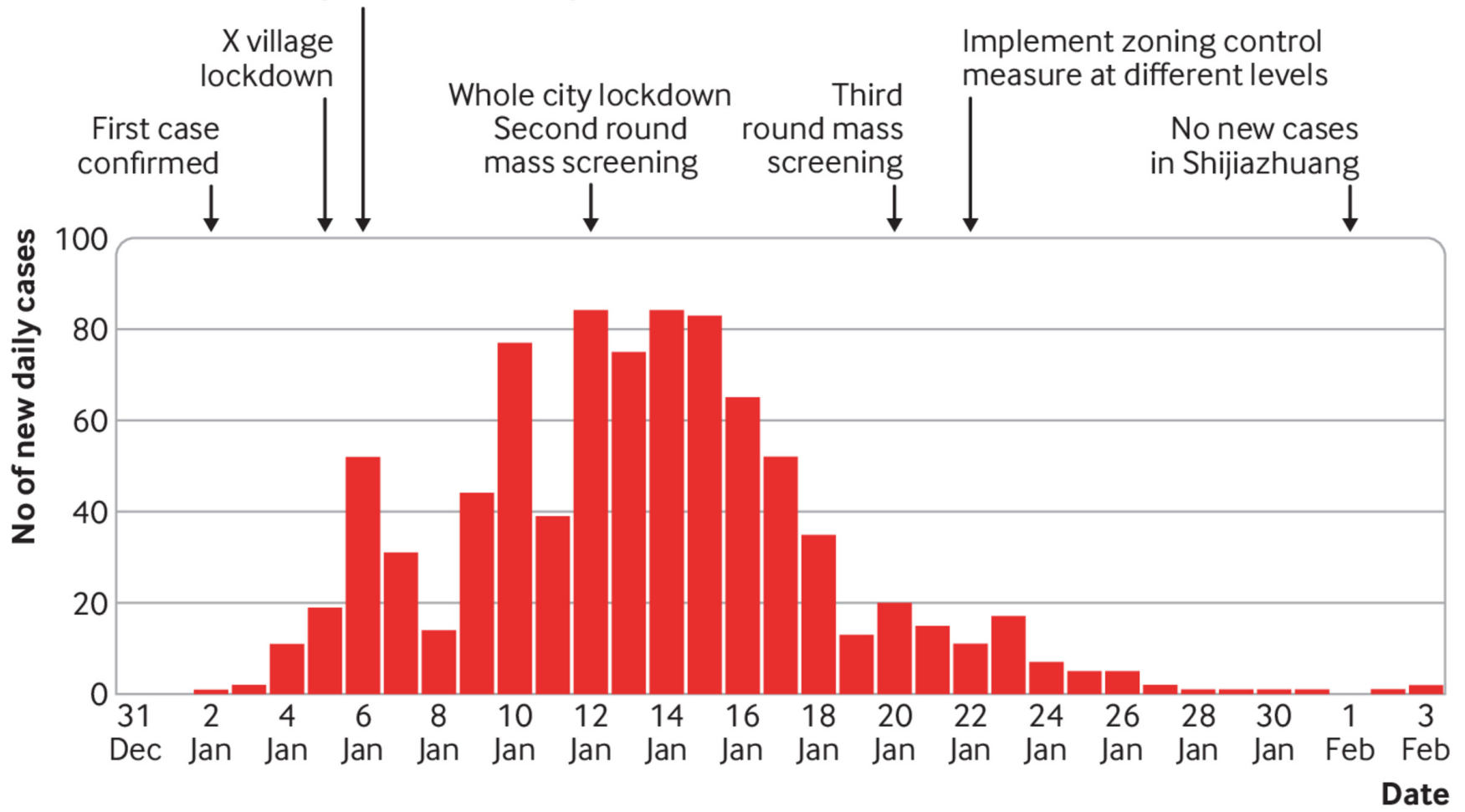

Fig 2 | Epi-curve and response to covid-19 outbreak in Shijiazhuang, China, January 2021. GC= Gaocheng

\section{Key messages}

- Successful containment of highly transmissible SARS-CoV-2 by several countries shows that elimination of an emerging virus that might lead to a pandemic can be achieved using non-pharmaceutical interventions alone at an early stage of an outbreak

- In an increasingly modernised and globalised world, innovative technological and organisational approaches can overcome feasibility, effectiveness, sustainability, and flexibility challenges of non-pharmaceutical interventions that are necessary for containment

- In comparison with strategies for covid-19 mitigation, rapid containment cost less, hastened socioeconomic recovery and normal functioning of the society, and provided better protection of a huge number of vulnerable lives

- Containment should be strongly attempted as the preferred initial response strategy to an emerging pathogen with potential to lead to a pandemic that might rapidly overwhelm medical systems

Contributors and sources: All authors have been involved in responses to the covid-19 pandemic or related studies. GFG has focused his research work on pathogen biology and immunology and is director general of the Chinese Centre of Disease Control and Prevention (China CDC), leading the China CDC emergency response against covid-19. QC has extensive experience in emergency response and epidemiological research related to infectious disease. LR is a senior adviser at China CDC with expertise in vaccinology and epidemiology. SL is interested in the research of human mobility and infectious disease transmission dynamics. GFG conceived the idea for this article. GFG and QC designed the framework of the article. QC developed the first draft using input from LR and SL. All authors contributed to the writing of subsequent versions. GFG is the guarantor.

Competing interests: We have read and understood BM/ policy on declaration of interests and have no relevant interests to declare.

Provenance and peer review: Not commissioned; externally peer reviewed.
This article is part of a collection proposed by the Peking University Centre for Public Health and Epidemic Preparedness and Response. Open access fees were funded by individual institutions. The $B M$ commissioned, peer reviewed, edited, and made the decision to publish. Li-Ming Li advised on commissioning for this collection. Jin-Ling Tang, Di Wang, and Kamran Abbasi were the lead editors for The BMJ.

QC is supported by Chinese National Science and Technology Major Project (No

2018ZX10101002-003-002), the Emergency Response Mechanism Operation Program, Chinese Centre for Disease Control and Prevention (131031001000015001), and the Public Health System Construction Project, Chinese Centre for Disease Control and Prevention (131031001000190045). SL is supported by the National Natural Science Foundation of China (81773498) and the Bill and Melinda Gates Foundation (INV-024911).

We thank Jinzhao Cui, Xiaokun Yang, Yishan Chen, Hongting Zhao, and Huimin Yang for their valuable input, including technical assistance in figure drawing and literature review.

1 World Health Organization. Coronavirus disease (COVID-19) weekly epidemiological update and weekly operational update. World Health Organization; 2021 [updated 23 March 2021; cited 26 March 2021]. https://www.who.int/emergencies/diseases/novel-coronavirus-2019/situation-reports.

2 Baker MG, Wilson N, Blakely T. Elimination could be the optimal response strategy for covid-19 and other emerging pandemic diseases. BMJ 2020;371:m4907. doi: 10.1136/bmi.m4907 pmid: 33561814

3 Lai S, Ruktanonchai NW, Zhou L, etal. Effect of non-pharmaceutical interventions to contain COVID-19 in China. Nature2020;585:410-3. doi: 10.1038/s41586-020-2293-x pmid: 32365354

4 Li Z, Chen Q, Feng L, etalChina CDC COVID-19 Emergency Response Strategy Team. Active case finding with case management: the key to tackling the COVID-19 pandemic. Lancet 2020;396:63-70. doi: 10.1016/S0140-6736(20)31278-2 pmid: 32505220

5 Jiang T, Wang H, Gao GF, Jiang X. Wearing face masks - the simple and effective way to block the infection source of covid-19. China CDC Wkly 2020;2:268-9. doi: 10.46234/ccdcw2020.069 pmid: 34594637

6 Liu J, Zhang L, Yan Y, etal. Excess mortality in Wuhan city and other parts of China during the three months of the covid-19 outbreak: findings from nationwide mortality registries. BMJ 2021;372:n415. doi: 10.1136/bmj.n415 pmid: 33627311 
7 National Health Commission of the People's Republic of China. The epidemic situation of coronavirus pneumonia by March 29th. National Health Commission of the People's Republic of China; 2021.

http://www.nhc.gov.cn/xcs/yqtb/202003/8721a8bc007b448db32489ea74b321f.shtml

8 Lazarus JV, Ratzan S, Palayew A, etal. COVID-SCORE: a global survey to assess public perceptions of government responses to COVID-19 (COVID-SCORE-10). PLoS One 2020;15:e0240011. doi: 10.1371/journal.pone.0240011 pmid: 33022023

9 The State Council Information Office of the People's Republic of China. Fighting COVID-19: China in action. China: The State Council Information Office of the People's Republic of China; 2020 [updated 7 June 2020; cited 26 March 202126th]. http://www.scio.gov.cn/zfbps/ndhf/42312/Document/1682142/1682142.htm.

10 Zhou L, Wu Z, Li Z, etal. One hundred days of coronavirus disease 2019 prevention and control in China. Clin Infect Dis 2021;72:332-9. doi: 10.1093/cid/ciaa725. pmid: 33501949

11 World Health Organization. Report of the WHO-China joint mission on Coronavirus Disease 2019 (COVID-19). https://www. who.int/publications-detail/report-of-the-who-china-joint-mission-oncoronavirus-disease-2019-(covid-19) (accessed 19 March 2020).

12 Li F, Li Y, Liu M, et al. Household transmission of SARS-CoV-2 and risk factors for susceptibility and infectivity in Wuhan: a retrospective observational study. Lancet Infect Dis 2021;21:617-28. PubMed doi: 10.1016/S1473-3099(20)30981-6pmid: 34423766

13 Pang X, Ren L, Wu S, etalCOVID-19 Field Response GroupCOVID-19 Laboratory Testing Group. Cold-chain food contamination as the possible origin of COVID-19 resurgence in Beijing. Natl SCi Rev 2020;7:1861-4. doi: 10.1093/nsr/nwaa264. pmid: 34676083

14 Li Z, Liu F, Cui J, et al. Comprehensive large-scale nucleic acid testing strategies support China's sustained containment of COVID-19. Nat Med 2021;27:740-2.

15 Bai L, Wang Y, Wang Y, Wu Y, Li N, Liu Z. Controlling COVID-19 transmission due to contaminated imported frozen food and food packaging. China CDC Wkly. 2021;3:30-3

16 Li Z, Guan X, Mao N, etal. Antibody seroprevalence in the epicenter Wuhan, Hubei, and six selected provinces after containment of the first epidemic wave of COVID-19 in China. Lancet Reg Health West Pac 2021;8:100094. doi: 10.1016/.lanwpc.2021.100094. pmid: 33585828

17 Tian H, Liu Y, Li Y, etal. An investigation of transmission control measures during the first 50 days of the COVID-19 epidemic in China. Science 2020;368:638-42. doi: 10.1126/science.abb6105. pmid: 32234804

18 The Joint Prevention and Control Mechanism of the State Council. National guidelines for prevention and control measures for work resumption of enterprises and in different risk areas. 2020. http://www.gov.cn/zhengce/content/2020-04/09/content_5500685.htm

19 The Joint Prevention and Control Mechanism of the State Council. Precise and refined guidance for community prevention, control and service work against COVID-19. April 14, 2020. http:/www.gov.cn/zhengce/zhengceku/2020-04/16/content_5503261.htm

20 The Joint Prevention and Control Mechanism of the State Council. Further notice on COVID-19 prevention and control work in key public areas, working units and key places. April 6, 2020. www.gov.cn/zhengce/content/2020-04/08/content_5500241.htm

21 The Joint Prevention and Control Mechanism of the State Council. Guiding opinions on the normalization of COVID-19 prevention and control. May 8, 2020. http://www.gov.cn/zhengce/content/2020-05/08/content_5509896.htm.

22 The State Council Information Office of the People's Republic of China. PCR testing: The Joint Prevention and Control Mechanism of the State Council in Response to the Novel Coronavirus Pneumonia. The work plan to further advance the capability building of novel coronavirus nucleic acid detection in China. China: The State Council Information Office of the People's Republic of China; 2020. http://www.gov.cn/zhengce/content/2020-08/31/content_5538788.htm.

23 Liu F, Zheng C, Wang L, etal. Interpretation of the protocol for prevention and control of COVID-19 in China (edition 8). China CDC Wkly 2021;3:527-30. doi: 10.46234/ccdcw2021.138. pmid: 34594927

24 Gao GF. From "A"IV to "Z"IKV: attacks from emerging and re-emerging pathogens. Cell 2018;172:1157-9. doi: 10.1016/j.cell.2018.02.025 pmid: 29522735

25 Stenseth NC, Dharmarajan G, Li R, Shi ZL, Yang R, Gao GF. Lessons learnt from the COVID-19 pandemic. Front Public Health2021;9:694705. doi: 10.3389/fpubh.2021.694705 pmid: 34409008

This is an Open Access article distributed in accordance with the Creative Commons Attribution Non Commercial (CC BY-NC 4.0) license, which permits others to distribute, remix, adapt, build upon this work non-commercially, and license their derivative works on different terms, provided the original work is properly cited and the use is non-commercial. See: http://creativecommons.org/licenses/by$n c / 4.0 \%$. 